\title{
A Importância da Afetividade Durante as Interações em Disciplinas Online
}

\section{Elaine Cristina Carvalho Duarte ${ }^{1}$}

${ }^{1}$ Campanha Nacional de Escolas da Comunidade - CNEC. SGAN Quadra 6 Módulo D - Brasília, DF - Brasil.

naneduarte@hotmail.com

\section{Resumo}

O presente artigo tem como proposta de estudo analisar o papel das ações afetivas na Educação a Distância (EaD) e a importância de refletir sobre as relações de afecção entre os agentes desse processo, tomando como referência os conceitos desenvolvidos por Baruch Spinoza sobre a questão da afetividade. Será proposta uma análise da Educação a Distância no sentido de mostrar a importância das relações afetivas entre os alunos, docentes e demais membros envolvidos nessa modalidade de ensino. Finalizando, serão discutidos aspectos relativos a uma disciplina em EaD que é oferecida para cursos presenciais em uma instituição de ensino superior, a fim de perceber como se estabelecem as relações de afecção entre os participantes desse processo. A metodologia utilizada para a pesquisa foi qualitativa. Foi aplicado um questionário para coleta de dados, que foram analisados, apresentados em forma de gráficos e discutidos. Também foram utilizados nesse estudo alguns e-mails de alunos trocados no decorrer da disciplina, bem como resultados da Comissão Permanente de Avaliação da instituição (CPA).

Palavras-chave: Educação a Distância. Afetividade. Ensino-aprendizagem. 


\section{The Importance of Affectivity During Interactions in Online Courses}

\section{Abstract}

The purpose of this article is to analyze the actions of affectivity in distance learning and the importance of reflecting on affective relationships between the participants of this process, taking as reference the concepts developed by Baruch Spinoza regarding affectivity. An analysis on distance learning will be proposed in order to show the importance of the affective relationships between students, teachers and other members involved in this learning system. Finally, aspects related to a course of a higher education resident program that is offered at a distance will be discussed to understand how affective relationships between the participants in this process are established. The methodology used for the research is qualitative. A questionnaire was applied to collect data that were analyzed, presented in graph form and discussed. Also, used in this study were e-mails from students exchanged during the course as well as results from the Institution's Permanent Evaluation Committee (CPA).

Keywords: Distance Learning. Affectivity. Teaching and learning.

\section{Introdução}

É inquestionável o caráter democrático da Educação a Distância (EaD). A possibilidade de oferecer cursos diversos em lugares onde o acesso à educação ainda é muito pequeno ou quase inexistente faz com que essa modalidade ganhe cada dia mais popularidade e notoriedade, incentivando as grandes universidades a apostar nessa forma de ensino.

Entretanto, se por um lado a expansão da EaD apresenta uma nova forma de pensar a educação na contemporaneidade, acompanhando as modificações sociais, por outro ela traz consigo o enorme desafio de romper o paradigma vigente, que já dura mais de dois séculos. Nesse sentido, para que essa realidade se torne cada vez mais eficaz, são muitos os modelos a serem superados e repensados para um bom ensino a distância. É necessária uma pedagogia direcionada para um ensino mediado por tecnologias, que se difere muito da pedagogia do ensino presencial - e ainda há muito a ser feito nessa direção. Assim, deve-se pensar em processos educacionais para um ensino a distância que seja efetivo e que atenda às necessidades dos educadores e dos educandos.

Sob essa perspectiva, dentre outras premências, surge a necessidade de possibilitar a criação de laços afetivos positivos em um ensino que é mediado por tecnologias. Ao passo que não há mais a presença física de professores e colegas, tornando o espaço-tempo relativo, faz-se necessário pensar uma possibilidade real de criação de afetos favoráveis, que são fundamentais para o aprendizado.

O conceito de afeto que será usado como base de discussão deste artigo é o conceito que Baruch Espinoza apresenta em sua obra Ética e que posteriormente é retomado por Deleuze em Espinoza - Filosofia prática. Para Spinoza, a afetividade é um ato que envolve um ou mais corpos; é a capacidade de se relacionar com o outro, de afetá-lo e ser afetado por ele em uma relação simbiótica. 
3. Por afeto compreendo as afecções do corpo, pelas quais sua potência de agir é aumentada ou diminuída, estimulada ou refreada e, ao mesmo tempo, as ideias dessas afecções.

Explicação. Assim, quando podemos ser a causa adequada de alguma dessas afecções, por afeto compreendo, então, uma ação; em caso contrário, uma paixão.

Postulados

1. O corpo humano pode ser afetado de muitas maneiras, pelas quais sua potência de agir é aumentada ou diminuída (SPINOZA, 2007, p. 1.628).

Spinoza vê o afeto como algo mais amplo, não apenas no sentido mais comum de paixão, mas também como ação. Desse modo, para o filósofo o afeto é um ato em que os sujeitos envolvidos são ativos dentro do processo. "Isso quer dizer que a noção de afeto comporta em si tanto a noção de ação quanto a de paixão, de maneira que, assim como podemos tratar de afetos passivos, podemos também tratar de afetos ativos" (JESUS, 2015, p. 162-163). Como o ser humano é um ser social, o afeto é um elemento crucial na convivência humana; esse processo de afecção é amplo e complexo. Qualquer ação de um corpo para outro pode ser considerada afeto.

Para Spinoza, todo corpo é capaz de afetar outro corpo e de ser afetado por ele. Relações de afecção e afetos são capazes desencadear o poder de ser afetado. "Quando um corpo X exerce uma ação sobre um corpo Z, o corpo X gera um traço no corpo Z. Afirma-se então que o corpo Z foi afetado pelo corpo X" (DUARTE, 2016, p. 3.508). Nesse sentido, Spinoza assevera que um corpo é definido pela capacidade de ser afetado, capacidade essa que é variável com a maneira como a ação é recebida na presença do afeto, transformando assim nossas potências de ação e pensamento. Deleuze, em sua obra sobre a filosofia de Spinoza, retoma essa ideia de afecção como ação que gera sensações:

Quando um corpo "encontra" outro corpo, uma ideia, outra ideia, tanto acontece que as duas relações se compõem para formar um todo mais potente, (...) sentimos alegria quando um corpo se encontra com o nosso e com ele se compõe, quando uma ideia se encontra com a nossa alma e com ela se compõe; inversamente, sentimos tristeza quando um corpo ou uma ideia ameaçam nossa própria coerência (DELEUZE, 2002, p. 25).

As afecções são situações de ações de um corpo sobre outro corpo; desse modo, há um corpo que age e outro que sofre a ação. Mas não equivale a dizer que essas afecções são passivas do ponto de quem recebe a ação, porque elas são uma troca de afetividade, sensibilidade e sensações, sejam elas positivas ou negativas, alterando nosso estado de potência.

Ao transportarmos esse princípio para as relações estabelecidas na EaD, podemos afirmar que qualquer ato, por menor que pareça, pode afetar a relação do aluno com o processo de aprendizagem. Como a Educação a Distância é construída de forma coletiva, ou seja, vários agentes de várias áreas participam das ações, é preciso que haja coesão entre a equipe para que os afetos sejam positivos. É necessário que todos os agentes da Educação a Distância estejam integrados aos princípios pedagógicos desse processo para transformar as "potências de ação e pensamento" do aluno em estimulo, em afetividades profícuas.

Ainda mais complexo é lidar com o ensino a distância das disciplinas oferecidas nesse formato nos cursos presenciais, ou seja, os $20 \%$ das disciplinas em EaD que podem ser ofertadas para esses cursos determinados pela Portaria $n^{\circ}$ 1.134, de 10 de outubro de 2016. A dificuldade de lecionar essas disciplinas se dá na grande resistência dos alunos com relação a elas. Um aluno que opta por cursar uma faculdade a distância já está predisposto a aceitar as regras que essa modalidade apresenta. Entretanto, um aluno que decide 
por um ensino presencial, na maioria das vezes, não está aberto para essa experiência, tornando-se ainda mais necessário criar uma afetividade positiva com esse aluno a fim de despertá-lo para essa nova forma de conhecimento. Portanto, as relações de afeto nesse transcurso devem ser as mais favoráveis possíveis.

Para discutir esse ponto é necessário, primeiramente, ater-se às especificidades da Educação a distância e ao papel de todos os agentes do processo. De forma diferente do ensino presencial, em que o professor é o único responsável pela sua disciplina, no sentido de pensar os modelos pedagógicos, escolher o material, montar os conteúdos, propor os modelos avaliativos etc., no ensino a distância existe uma equipe que é responsável pela elaboração, construção, organização e aplicação das aulas.

O intuito deste artigo foi realizar um estudo sobre as ações de afecção existentes no ensino a distância. Para isso foi realizada uma análise de uma disciplina em EaD de um curso presencial de uma instituição de ensino com várias unidades de ensino espalhadas pelo país; a disciplina é ofertada nesse formato para todas as unidades. Foram utilizados questionários para perceber a posição dos alunos com relação à interação no ambiente virtual de aprendizagem (AVA). Com base nesses dados e no referencial teórico utilizado, buscou-se compreender parte dos laços afetivos em Educação a Distância. Os dados coletados para análise foram de uma disciplina de um curso presencial que tem $20 \%$ das disciplinas ofertadas em EaD em uma instituição de ensino superior, a fim de mapear quais procedimentos e ações do curso afetam o seu processo educacional.

\subsection{Fundamentação Teórica}

Uma das principais vantagens do ensino a distância, sem dúvida, é a possibilidade de oferecer educação em lugares variados, inclusive naqueles pontos distantes em que não há faculdade. Alunos de cidades pequenas, que não vislumbravam formação superior, atualmente estão podendo fazer sua graduação graças à EaD, que possibilita a democratização do ensino por não requerer a presença do aluno diariamente na escola.

Outra grande vantagem da EaD é a possibilidade de oferecer cursos a pessoas que não têm disponibilidade de tempo diário de frequentar sala de aula. A flexibilidade de tempo tem sido um dos motivos pelos quais muitos alunos, tanto de graduação como de pós-graduação, têm procurado os cursos a distância.

Apesar dessas vantagens, os índices de evasão em um curso a distância são muito maiores que os de um curso presencial. É perceptível a diferença entre a evasão dos cursos presenciais e a dos cursos semipresenciais com relação aos cursos a distância ${ }^{1}$. Nesse sentido, pode-se afirmar que um dos maiores desafios das instituições que oferecem essa modalidade de ensino é manter o aluno no curso. Os motivos pelos quais essa evasão acontece são vários; entretanto, apresentaremos apenas um dos pontos, que é o foco deste trabalho.

Silva e Figueiredo (2012, p. 3) afirmam que

a evasão de alunos na EaD, na maioria dos casos, está relacionada aos seguintes fatores: falta de motivação diante da responsabilidade quanto à autoaprendizagem, a rarefeita relação com os professores e colegas, que resulta na falta de afetividade e de percepção de pertencer a um grupo e, por fim, o pouco dinamismo dos encontros presenciais. $\mathrm{O}$ estímulo ao contato entre todos os envolvidos (tutores, alunos e professores) é essencial para ampliar a confiança e o ânimo para utilizar ambientes virtuais e concluir o curso EaD.

1 Sobre esse assunto é possível consultar o Censo da Abed: Censo EAD BR 2016 - Relatório analítico da Educação a Distância no Brasil, p. 153. Disponível em: http://abed.org.br/censoead2016/Censo_EAD_2016_portugues.pdf. Acesso em: 14 nov. 2018. 
Esse texto explica um dos motivos que levam um aluno a abandonar as aulas a distância. Um dos pontos que desmotiva os discentes da EaD é o pouco contato com professores, tutores e colegas, o que cria a necessidade de estabelecer sozinho uma rotina de estudos, fazendo com que boa parte dos envolvidos nos cursos não siga em frente, por se sentirem desestimulados. O ser humano é um ser sociável, que vive em tribo desde os primórdios da sua existência; por esse, motivo agrupá-los é um fator fundamental para qualquer atividade que envolva relações humanas. Outro ponto são as constantes falhas no processo: desde problemas administrativos a problemas técnicos, assuntos que serão discutidos mais à frente.

Moran (1994, p. 39) afirma que nosso sistema educacional, de modo geral, está condicionado ao racionalismo, não sendo capaz de abarcar todas as instâncias que compõem o ser humano. Essa racionalização é fruto da filosofia idealista e do pensamento judaico-cristão que predominam na sociedade ocidental. Dessa forma, o homem é visto como um ser dividido entre "corpo e mente, material e espiritual, razão e afeto, supervalorizando o intelectual-espiritual e desprezando o sensorial afetivo".

Mendes Netto e Perpétuo (2010) afirmam que, para Jean Piaget, o afeto é parte fundamental da inteligência; não há aprendizado sem afeto. Henri Wallon (2005) também destaca a importância da afetividade no aprendizado, uma vez que ela, assim como a inteligência, evolui, se constrói e se modifica ao longo do desenvolvimento. Vygotsky (1999), embora não fale diretamente de afetividade, deixa clara a sua importância quando evidencia em sua abordagem sociointeracionista que o ser humano é um ser biológico social; portanto, seu desenvolvimento está intimamente ligado ao afeto.

Assim, quando pensamos em uma educação mais globalizante e efetiva, não há como dissociar cognição de afetividade, porque não há aprendizado sem trocas afetivas, porque o afeto, como mencionado por Spinoza, aciona nossas potências de ação.

Quando falamos em EaD, essa questão se torna ainda mais patente, uma vez que a "não presença" das aulas a distância pressupõe uma forma diferente de afetividade com a qual os envolvidos no processo ainda não estão completamente familiarizados. Por essa razão, é preciso pensar com ainda mais cuidado na questão da afecção quando falamos em Educação a Distância, pois ela pode ser o diferencial no processo educacional do curso, afinal a ação afetiva acontece todas as vezes que um corpo aciona outro corpo. Por essa razão, é fundamental que a afecção positiva seja pensada, programada e construída de forma consciente, caso contrário ela poderá intuitivamente causar sensações negativas, ou seja, a ausência de afecções favoráveis pode gerar afecções desfavoráveis, uma vez que o aluno pode interpretar a falta de estímulos positivos como algo adverso. Desse modo, é importante cuidar para que o conhecimento pedagógico seja estendido a toda a equipe que integra o processo de $\mathrm{EaD}$, desde o pessoal de tecnologia da informação (TI) ao pessoal administrativo.

Normalmente as instituições de ensino estão sempre incomodadas com o "fantasma" chamado evasão. Não basta investir em tecnologias para ofertar bons serviços, mas criar estratégias e desenvolvê-las para otimizar os efeitos causados e superar os riscos da evasão. Para Bonatto (2008, p. 3), "geralmente as instituições se preocupam e investem muito mais nas tecnologias de comunicação e na qualidade estética dos produtos e serviços oferecidos".

Nesse sentido, na Educação a Distância, um aspecto considerado importante para a continuidade do aluno no curso está relacionado à afetividade, diante das relações estabelecidas entre aluno e tutor, o que pode resultar em uma aprendizagem significativa (CAMPOS; MELO; RODRIGUES, 2017, p. 4). 
Esse texto corrobora a ideia de que, em geral, as instituições de ensino se preocupam com os aspectos tecnológicos dos cursos ofertados e colocam em segundo plano as dimensões mais humanísticas dos serviços oferecidos aos alunos em um curso ou disciplina em EaD. É fundamental que se reflita e que se estabeleçam estratégias para aprofundar as relações humanas via aparatos tecnológicos. Afinal, embora a máquina faça a intermediação do processo, o produto final são os humanos: alunos, tutores, professores etc.

Sapucaia (2017, p. 3) afirma que, com o crescimento da EaD, houve "engajamento de diversos profissionais das áreas tecnológicas e de comunicação no desenvolvimento de sistemas, conteúdos e mídias para EaD, em muitos casos sem terem o conhecimento pedagógico necessário para atuar nessa área". Desse modo, é muito comum vermos que há preocupação em capacitar a equipe pedagógica para fazer uso dos recursos tecnológicos, mas pouco se veem capacitações pedagógicas para a equipe de tecnologia da informação (TI), por exemplo. Isso acaba por gerar uma equipe de tecnologia despreparada para lidar com as vicissitudes que o processo pedagógico em EaD apresenta, levando os alunos a reclamar com frequência dos atendimentos oferecidos pelo pessoal responsável pela área técnica. E se, como afirmam Spinoza e Deleuze, o processo de afecção se dá por meio de ações entre os corpos, é imprescindível incluir no processo educacional de um curso em EaD a questão da afetividade e do envolvimento de toda a equipe com essa questão, pois todas as ações do processo causam afecção. O conhecimento é uma troca de informações entre um e outro indivíduo e entre indivíduo e meio social. Quando pensamos em um ambiente virtual de aprendizagem, temos que pensar na sua representatividade como meio, pois é ele quem faz as mediações das informações e das relações e não há aprendizado sem afetividade. Sendo assim, é fundamental pensar nas ferramentas que temos à nossa disposição para desenvolver uma relação de afecções positivas entre os agentes do processo de EaD, visando maior eficácia do aprendizado e da aquisição de conhecimento.

De um modo um pouco diferente do que acontece com a educação presencial, como já mencionado, na Educação a Distância as aulas são planejadas, preparadas e ministradas por uma equipe multidisciplinar. Há profissionais das áreas de Educação, webdesigners, videomakers, designers instrucionais, sistemas de informação e comunicação e comunicação social, dentre outros eventualmente necessários para que se ofereça uma aula a distância de qualidade. Ao contrário da educação presencial, em que o professor é praticamente o único responsável por sua matéria, na EaD essa responsabilidade fica diluída entre todos os atores do processo. As aulas são pensadas de maneira integrada por toda a equipe. Há uma estrutura bastante complexa, que envolve muitos profissionais de diferentes áreas.

Como na EaD as aulas não são de responsabilidade única do professor, e como todos os agentes do processo estão de alguma forma envolvidos com o produto final, que é o aprendizado do aluno, é fundamental que o grupo tenha relação de proximidade com esses alunos, produzindo afeto e gerando confiança, pois a afetividade gera confiabilidade.

\section{Metodologia}

A metodologia utilizada foi qualitativa. Qualitativa porque os instrumentos para coleta dos dados foram a observação e a análise de conteúdo, como e-mails trocados entre alunos, professora e tutora, respostas abertas da comissão permanente de avaliação (CPA) da instituição e um questionário respondido por alunos da disciplina.

O estudo foi desenvolvido observando as seguintes etapas: primeiro foi feita uma pesquisa bibliográfica para ampliar os textos de fundamentação teórica. Em seguida aplicou-se um questionário aos alunos de uma disciplina em EaD de um curso presencial de uma instituição de ensino que possui várias unidades espalhadas pelo país. Esse questionário foi online, com perguntas de múltipla escolha e uma 
aberta, utilizando o Google Drive, que pode ser acessado no endereço https://docs.google.com/forms/d/e/ 1FAIpQLScv 3bTT cUiOW2eQz85TUojqZwR6Glj XsivHDgzSjfPTwUA/viewform?c=0\&w=1. Os alunos foram contatados por e-mail e convidados espontaneamente a responder ao questionário. Por fim, depois de coletados, os dados foram analisados levando em consideração o referencial teórico utilizado. Também foram utilizados e-mails de alunos trocados com a professora e a tutora no decorrer da disciplina e os resultados da CPA para corroborar os dados coletados pelo questionário.

Os sujeitos do estudo foram 104 alunos que responderam ao questionário, 96 alunos que responderam à CPA e alguns alunos que trocaram e-mails com a professora e a tutora no decorrer da disciplina. A faixa etária dos respondentes é variável, tendo alunos de 18 anos em diante.

\section{Resultados e Discussão}

\subsection{Elementos de afecção}

Os dados para análise foram coletados de uma das disciplinas em EaD que representam os $20 \%$ de disciplinas a distância permitidas pelo MEC em cursos presenciais. A disciplina faz parte do currículo básico dos cursos, é ofertada no segundo período e é ministrada para 18 cursos de diversas áreas de ensino. Ela é semestral e tem carga horária de $60 \mathrm{~h}$. O modelo de design instrucional (DI) é misto ${ }^{2}$, mas o professor tem pouca autonomia para diversificar as aulas.

O ambiente de aprendizagem utilizado é o Moodle 3.4 e apresenta poucos recursos de interatividade síncrona. As atividades são essencialmente de múltipla escolha, tendo apenas duas atividades semestrais de produção textual que são corrigidas pelo professor da disciplina. As aulas são apresentadas aos alunos em forma de slides e vídeos pré-gravados pela professora conteudista. A professora responsável pela disciplina tem permissão para modificar o conteúdo das aulas, entretanto as modificações devem ser feitas antes do início dos semestres e devem seguir um roteiro preestabelecido. Não é permitida a utilização nem a indicação de vídeos externos, como Youtube ou Vimeo. Todos os vídeos da disciplina devem ser gravados no estúdio do Centro de Educação a Distância (CEAD) e devem seguir um roteiro padrão. Ao professor responsável é apenas permitido gravar áudios para os alunos, modificar as discussões do fórum, as questões das atividades de aprendizagem e as atividades avaliativas.

As ferramentas de interatividade do ambiente virtual de aprendizagem (AVA) são o fórum de discussão e o chat. Infelizmente não existe uma ferramenta para que o professor realize web aulas; o contato síncrono do professor fica restrito ao chat. A ausência de web aulas é uma reclamação dos alunos tanto no questionário quanto na comissão permanente de avaliação, como registra o texto de um aluno deixado no questionário da CPA: “As aulas são muito chatas. O que salva é a professora, que é muito legal e atenciosa. Também não entendo como não tem web aulas ao vivo. Uma disciplina em EaD deveria ter web aulas para ajudar a sanar as dúvidas dos alunos".

Como a disciplina a distância não oferece a presença física, nota-se, pelas respostas dos alunos nos instrumentos utilizados, que desejam, de algum modo, ter o professor por perto. Nas disciplinas em EaD que compõem os $20 \%$ das disciplinas dos cursos presenciais, observa-se que os alunos, por estarem acostumados com o professor em sala de aula, têm dificuldade grande de se adaptar a um aprendizado mais autônomo, que é a característica primordial da Educação a Distância. Eles de fato sentem falta da presença. Em muitos casos, os alunos acabam por interagir virtualmente com discentes que não são seus colegas

2 Segundo Andrea Filatro (2008, p. 19-21) no modelo de design instrucional misto o conteúdo das aulas e as atividades são preparados especialmente para o curso e as avaliações são, em sua grande maioria, automatizadas. Entretanto, é permitido o uso de links para conteúdos externos que sejam pertinentes ao assunto desenvolvido nas aulas. A aprendizagem é autogerida e o direcionamento é dado para a aprendizagem individual. A função da tutoria se resume a tirar dúvidas dos alunos e ajudá-los com problemas pontuais como acesso e dificuldade em acessar o conteúdo, dentre outros. 
no ensino presencial, que são de outros cursos e de outras cidades, uma vez que a disciplina é oferecida para todas as 18 unidades de ensino que compõem a instituição e que estão em diversos lugares do país. Sob essa perspectiva, torna-se ainda mais importante por parte da professora da disciplina e dos demais envolvidos no processo criar laços que integrem esse aluno, que deem a ele sensação de pertencimento.

O Gráfico 1 mostra as percentagens das respostas sobre experiência com disciplinas em EaD.

Gráfico 1: Tempo de experiência do discente com EaD

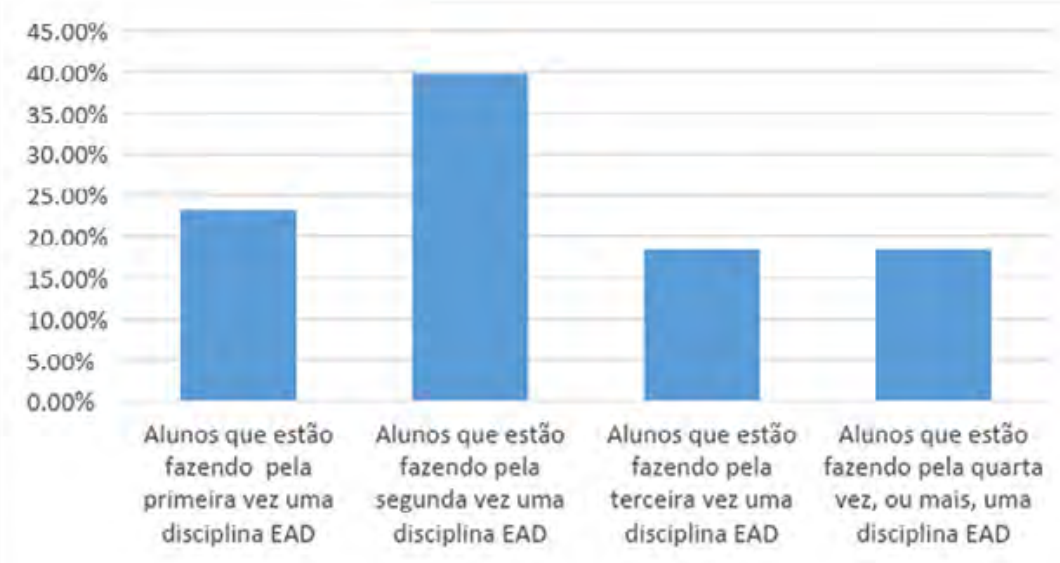

Dos alunos que responderam ao questionário, 39,8\% estavam cursando sua segunda disciplina online, $23,3 \%$ cursando pela primeira vez, $18,4 \%$ cursando pela terceira vez e $18,4 \%$ cursando pela quarta vez uma disciplina em EaD.

Por ser uma disciplina ofertada no segundo período do curso, é notável a dificuldade de alguns alunos em compreender o funcionamento das aulas, por ser em EaD. Muitos desses alunos nunca tiveram contato com um ambiente virtual de aprendizagem antes, porque estão cursando uma disciplina a distância pela primeira vez, então muitos deles necessitam de ajuda mínima para navegar no AVA e assimilar os comandos dos links. Nesse sentido, toda a equipe responsável pelo andamento das aulas necessita se preparar para auxiliar os alunos com essas demandas, de forma que o professor responsável não apenas se encarrega do conteúdo ministrado, como também dos aspectos tecnológicos e até administrativos do curso, resolvendo muitas vezes problemas gerados pela secretaria, por exemplo, que são reclamações muito frequentes dos alunos. Quando questionados sobre a rapidez das resoluções dos problemas relativos ao setor administrativo da instituição de ensino, e o quanto isso interfere no andamento da disciplina, as respostas foram as seguintes:

Gráfico 2: Influência do setor administrativo nas disciplinas em EaD

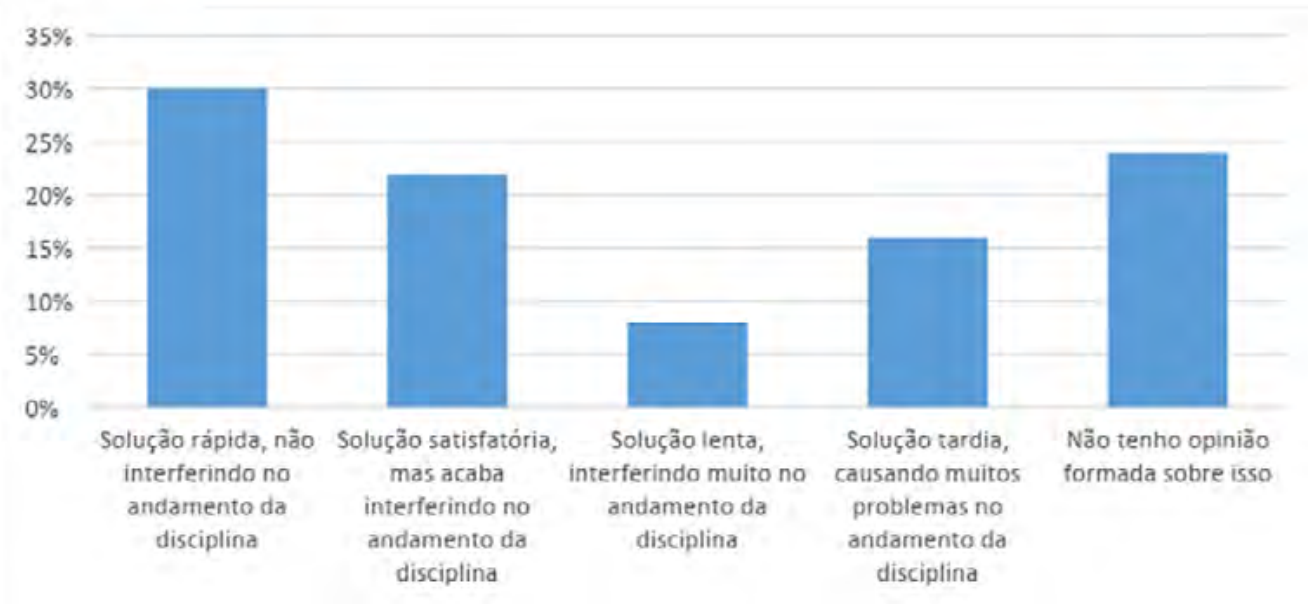


Sobre as respostas, 30\% dos alunos argumentaram que os problemas gerados pelas áreas administrativas relativos às disciplinas em EaD são resolvidos rapidamente e não interferem no andamento das aulas; $22 \%$ acham que a administração da sua unidade resolve as questões ligadas à EaD de maneira satisfatória, mas que os problemas gerados por eles interferem no andamento do curso; $8 \%$ afirmam que o setor administrativo resolve as coisas de maneira lenta e isso interfere muito no andamento da disciplina; $16 \%$ estão muito insatisfeitos com a maneira como o setor administrativo resolve os problemas relativos à EaD e vê isso como um problema grande no andamento da disciplina; e $24 \%$ dizem não ter opinião formada sobre o assunto.

Tendo em vista que a entrada do aluno na disciplina depende da correta matrícula do aluno na secretaria, é bastante comum alunos entrarem com atraso no ambiente virtual de aprendizagem em virtude de erros na matrícula. Esse tipo de ocorrência não é incomum, e alguns alunos chegam a desistir da disciplina por razões como essa. Outros se vêm prejudicados e se apoiam no coordenador, no professor e no tutor. Com base nos dados coletados, podemos inferir que $46 \%$ dos alunos acreditam que falhas no setor administrativo atrapalham de alguma forma o andamento da disciplina, o que é um valor muito significativo. $\mathrm{Na}$ pergunta aberta proposta no questionário e em e-mails trocados com os alunos, muitos reclamaram do atendimento das secretarias. Desse modo, junto com os problemas técnicos, os problemas gerados pelo setor administrativo, mais especificamente a secretaria, são as duas maiores reclamações dos discentes.

É nesse sentido que se faz necessária uma ação bastante incisiva dos responsáveis pelo processo, uma vez que essas disciplinas funcionam em cadeia, ou seja, cada setor tem seu papel muito bem delineado e imprescindível no funcionamento das aulas, e um problema em um dos nós da rede pode interferir em outros pontos do processo. Assim, deve-se atentar para todos os segmentos a fim de propor métodos que organizem e minimizem esses erros. Como se trata de disciplinas em EaD para cursos presenciais, e as responsáveis pelas matrículas dos alunos são as secretarias das unidades e não o CEAD, é preciso que se padronizem esses aspectos, de forma que as secretarias ajam individualmente, mas de forma padronizada, minimizando os erros e otimizando todo o processo.

Outro aspecto importante que pode ser observado nos comentários dos alunos é que, embora o erro seja do setor administrativo, para o aluno a resolução deve vir do professor ou do centro de EaD. Se a secretaria atrasa a matrícula, o problema acaba se tornando não do setor administrativo, mas sim do CEAD, pois quem tem que lidar com as dificuldades do aluno são professores, tutores e coordenadores da EaD, exemplificando claramente que a reclamação dos alunos de que problemas no setor administrativo interferem muito no andamento da disciplina.

Além dos problemas gerados pelo setor administrativo, outro setor que foi bastante mencionado pelos alunos, foi o de tecnologia da informação (TI). Quando questionados sobre a rapidez com que essa equipe resolve os problemas e como isso interfere no andamento da disciplina, as respostas foram estas:

Gráfico 3: Influência do setor de TI no andamento da disciplina

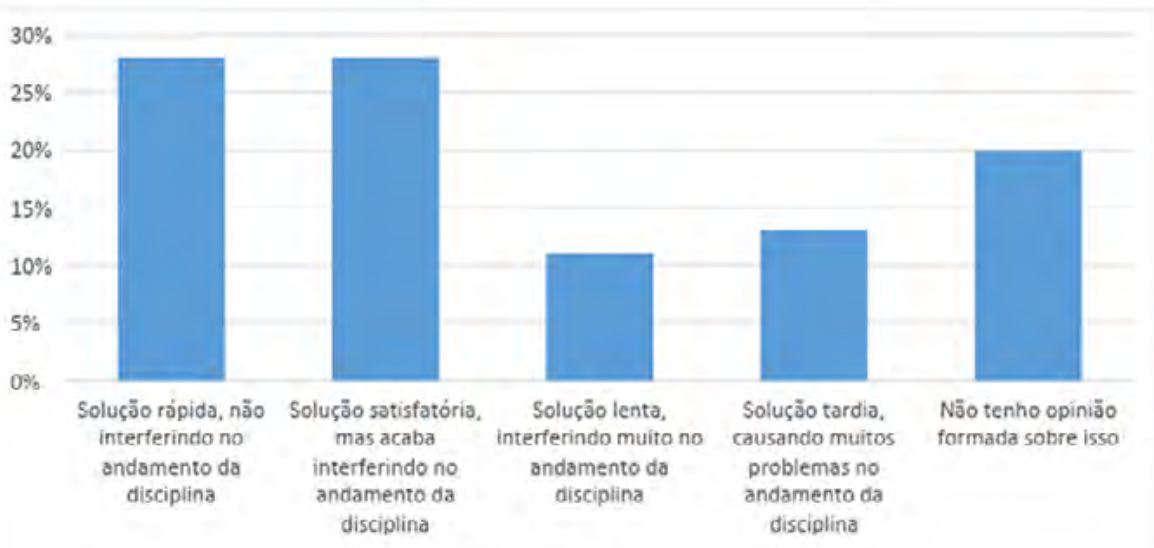


Sobre as respostas, $28 \%$ dos alunos afirmam que a equipe de TI é rápida em responder ao aluno quando solicitada; outros $28 \%$ acham que a equipe de TI responde em tempo satisfatório, mas que o tempo levado para responder ao aluno acaba interferindo no andamento da disciplina; $11 \%$ dos alunos acreditam que a equipe de TI é muito lenta ao responder às solicitações dos alunos e que isso atrapalha muito o andamento da disciplina; $13 \%$ dos alunos afirmam que a equipe de TI responde muito tardiamente aos questionamentos dos alunos, o que causa problemas no andamento da disciplina; e 20\% não têm opinião formada sobre o assunto. Portanto, $52 \%$ dos alunos acreditam que os problemas gerados pela TI interferem no andamento da disciplina. Ainda sobre os problemas relacionados à $\mathrm{TI}$, quando questionados sobre os problemas gerados pelo não acesso ao ambiente virtual de aprendizagem (AVA), as respostas foram as seguintes:

Gráfico 4: Influência de problemas no acesso ao AVA na motivação da disciplina

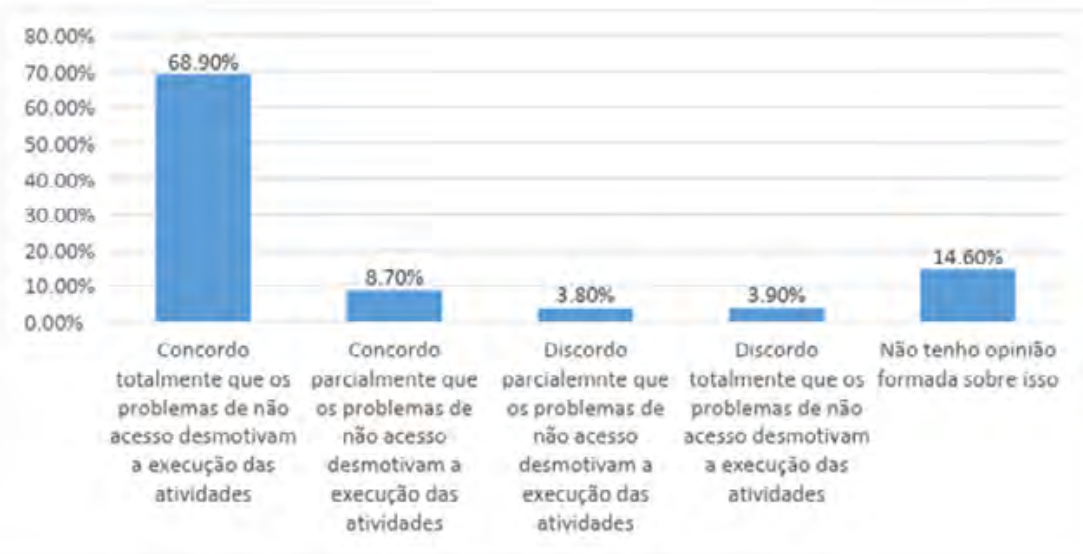

Nota-se que $68,9 \%$ dos alunos afirmam que problemas de acesso ao AVA desmotivam a execução das atividades; $8,7 \%$ acham que esses problemas desestimulam um pouco a execução das atividades; $4,2 \%$ acreditam que desmotivam muito pouco a execução das atividades; 3,7\% acham que tais problemas não desmotivam a execução das atividades; e 14,6\% não têm opinião formada sobre o assunto. Vê-se que os alunos ficam desestimulados quando tentam acessar o AVA e não conseguem por problemas técnicos. Tendo em vista que, em sua grande maioria, são pessoas que conciliam o estudo com trabalho, as faIhas do sistema, especialmente à noite e nos fins de semana, comprometem o planejamento de estudos desses alunos, que muitas vezes utilizam o tempo livre nesses horários para realizar as atividades. Outra reclamação grande com relação ao sistema é o não adiamento de atividades quando ocorre instabilidade do sistema. Muitas vezes, a fim de cumprir os prazos determinados no calendário, mesmo quando há problemas no sistema, os prazos das atividades não sofrem alterações, e o aluno vê nessa prática um descaso da equipe para com ele.

Em e-mail trocado entre um aluno e o professor da disciplina no dia 03 de abril de 2018, o aluno manifestava o desejo de trancamento da disciplina por problemas não resolvidos pelo setor administrativo e TI: "Entrei em contato com a secretaria; eles não irão conseguir liberar o acesso à matrícula antes do dia 15/04. Como devo proceder, pois perderei essa atividade? Caso não exista a possibilidade de postergar, irei trancar essa matéria".

Quando tomamos as reclamações dos alunos referentes aos setores administrativos e TI, pode-se constatar a importância dos laços afetivos para o aprendizado do aluno. Quando surge alguma dificuldade, a primeira medida tomada é procurar o professor, o tutor da disciplina ou o coordenador do curso. Em vários depoimentos, evidencia-se que os alunos veem nesses agentes do processo credibilidade, acessibilidade e principalmente confiança. Eles acreditam que os professores e coordenadores irão auxiliá-los. Sob essa ótica, é importante também incentivar o envolvimento de toda a equipe com os alunos, a fim de criar laços de credibilidade. É patente que as relações entre alunos e professores é mais estreita do que a 
dos alunos com os demais agentes do processo, pela própria natureza do vínculo estabelecido entre eles, que se constrói especialmente na proximidade. Entretanto, tomando o afeto sob o prisma de Spinoza e Deleuze, de afecção entre os corpos, é importante que todos os setores envolvidos na EaD criem ligações com os docentes a fim de gerar confiabilidade além do setor pedagógico.

O aluno precisa confiar na equipe como um todo para se sentir motivado e amparado; precisa ter certeza de que todos os agentes do processo estão direcionados para o aprendizado dele, que é o produto final de todo o segmento. O pessoal dos setores administrativo, de TI, de avaliação, de DI devem se inteirar das necessidades do aluno para propor um modelo de curso que atenda os anseios desses alunos. Por isso, é fundamental que toda a equipe se preocupe com os questionamentos e posicionamentos dos discentes.

É sob essa perspectiva que se deve levar em consideração os apontamentos dos alunos. Quando eles ressaltam que se sentem prejudicados quando entram atrasados na disciplina ou que não conseguem fazer uma atividade no AVA por problemas do sistema, estão na verdade sinalizando que esses setores não se preocupam com eles tanto quanto deveriam; portanto, há um afeto negativo. Eles desejam ter seus problemas resolvidos, eles querem ser parte do processo como um todo, eles desejam ter seus e-mails e questionamentos respondidos.

Nesse sentido é que se entendem importantes as relações de afeto. Educação mediada por tecnologias, por sua natureza, gera problemas técnicos, mas é fundamental que o aluno tenha a confiança nos responsáveis pelo processo. Ele precisa da segurança de que seus problemas serão sanados sem prejuízo do seu aprendizado.

A morosidade em responder aos questionamentos é algo que certamente gera muita falta de confiabilidade. Quando questionados se a celeridade de professores e tutores para responder aos questionamentos dos alunos é fundamental para a motivação no processo de aprendizado, as respostas foram as seguintes:

Gráfico 5: Influência da celeridade de atendimento dos professores e tutores

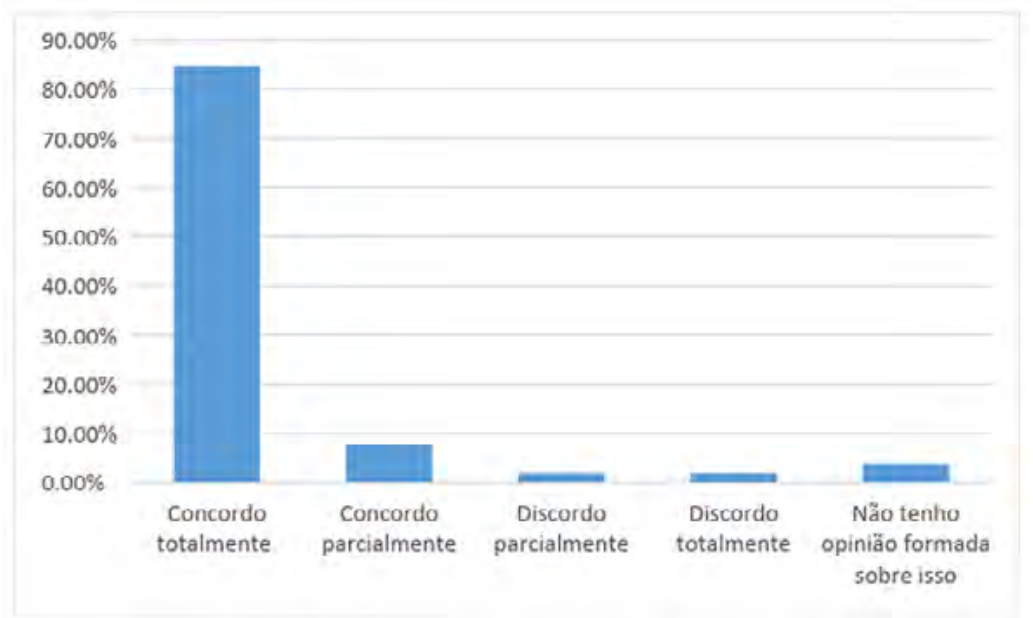

No questionário, 92,3\% dos alunos afirmaram que é muito importante a resposta rápida do professor ou tutor para manter a motivação do aluno; 92,5\% dos alunos acreditam que um professor que se envolve com a disciplina e com o aprendizado dos alunos influencia na motivação desses alunos durante o curso. Para $77,7 \%$ dos respondentes, um professor e um tutor que estimulam o aluno com frequência ajudam no bom desempenho do discente.

Esses dados corroboram a ideia de que a atuação do professor é fundamental para a motivação do aluno em uma aula em EaD. "Ambientes acolhedores, com mediadores afetivos, são importantes para que se estabeleça confiança mútua: seja entre tutores e alunos ou entre alunos e alunos. Havendo confiança há 
mais interesse, e havendo interesse há maior incentivo por parte do próprio aluno para sua autonomia" (GOMURY, 2018). Uma vez que essa modalidade de ensino se vale muito da autonomia, é interessante observar que, mesmo o aluno tendo que estudar sozinho, a figura do professor é fundamental, porque representa o laço humano que o aluno estabelece em uma disciplina mediada por um computador.

O comprometimento afetivo do aluno com relação ao curso é proveniente de suas experiências, principalmente as positivas, que fazem com que ele se sinta bem e competente e deseje permanecer no curso. (...)

Existe um caráter subjetivo do dever de reciprocidade, no qual quem recebe algo se sente devedor e acredita que deve retribuir de alguma forma àquilo que recebeu. A maneira de retribuir, do aluno, é permanecer, se dedicar e ser aprovado no curso (GODOI; MIRANDA, 2018, p. 3-4).

Godoi e Miranda expressam a ideia de que os laços afetivos positivos são fundamentais, e esses laços devem ser construídos na reciprocidade. Um aluno que se sente acolhido em sua disciplina em EaD se sentirá no dever de retribuir esse acolhimento em forma de dedicação ao curso. É nesse sentido que os alunos julgam importante a "presença" dos agentes do processo; eles querem receber o que lhes é prometido para então corresponder de maneira positiva ao que lhes é entregue. Se a equipe oferece a eles afetos positivos, em retorno eles darão afetos positivos. Portanto, acolher os alunos, participar da vida estudantil deles e atribuir ao processo de aprendizagem afecções assertivas é fundamental para o bom desempenho dos alunos nas disciplinas online.

\section{Considerações Finais}

Ao longo deste artigo discutimos o quão importante é o relacionamento estabelecido entre alunos de disciplinas em EaD, professores, tutores e demais agentes envolvidos no processo. Esclareceu-se que gerar afetos positivos durante as aulas é fundamental para manter o interesse do aluno na disciplina e para seu aprendizado. Quanto maiores e mais positivas forem as correspondências afetivas, maior será o interesse do aluno e melhor será o seu desempenho.

Sob essa perspectiva, buscou-se discutir e elucidar a importância de pensar em ações que abarquem a integração entre todos os agentes do EaD com os discentes.

Em geral essa relação de afetividade e integração fica a cargo apenas dos professores e tutores; entretanto, é necessário que toda a equipe responsável pela criação de um curso em EaD esteja também direcionada para a importância do seu papel nessa cadeia e no quanto suas ações afetam os alunos.

Esse levantamento deve ser feito por meio de questionário respondido pelos alunos, em conversas constantes entre os professores, tutores e demais membros da equipe para saber quais as reclamações mais pontuais e constantes dos alunos. De posse dessas informações, a equipe deve refletir sobre as ações que minimizem os problemas.

É importante frisar que, depois do levantamento feito por este artigo, observou-se que especialmente a equipe de TI e o setor administrativo não estão preparados para lidar mais diretamente com as reivindicações dos alunos. Não se trata de resolver os problemas dos alunos momentaneamente; é fundamental dar um retorno, dar uma satisfação, pois ficou claro pela análise dos dados que os alunos se sentem desanimados quando não recebem informações sobre seus problemas; é preciso mostrar para o aluno que sua reivindicação está sendo analisada, que haverá uma solução. 
Retomando um assunto já discutido no início do texto, em uma citação de Campos, Melo e Rodrigues, com a grande quantidade de profissionais das áreas tecnológicas migrando para a área educacional, é fundamental que se propiciem capacitações pedagógicas para esses membros da equipe. Assim como há preocupação em capacitar a equipe pedagógica para o manejo dos aparatos tecnológicos, é preciso também capacitar a equipe tecnológica e a administrativa para lidar de forma pedagógica com os alunos. Dessa forma, estaremos cada vez mais próximos de uma EaD de qualidade e que abarque todas as possibilidades do mundo virtual.

\section{Referências Bibliográficas}

CAMPOS, Ilka; MELO, Marcia Meireles; RODRIGUES, Joventina. Educação a distância: o desafio da afetividade na percepção de tutores e alunos. In: CONGRESSO INTERNACIONAL ABED DE EDUCAÇÃO A DISTÂNCIA. Anais... Foz do Iguaçu: ABED, 2017, p. 1-10. Disponível em: < http://www.abed.org.br/hotsite/20-ciaed/pt/anais/pdf/268.pdf>. Acesso em: 15 abr. 2019.

DELEUZE, Gilles. Espinosa: Filosofia prática. Trad. Daniel Liens e Fabien Liens. São Paulo: Escuta, 2002.

DUARTE, Elaine C. C. Modulações técnicas: a construção de sentido na telenovela Roque Santeiro, de Dias Gomes. In: XV CONGRESSO INTERNACIONAL ABRALIC. Anais... Rio de Janeiro: UERJ, 2016, p. 3.5063.515. Disponível em: <http://www.abralic.org.br/anais/arquivos/2016 1491414941.pdf>. Acesso em: 12 fev. 2019.

FIGUEIREDO, Vitor F.; SILVA, Camila G. Ambiente virtual de aprendizagem: comunicação, interação e afetividade em EAD. Aprendizagem em EAD, Brasília, v. 1, n 1, p. 1-16, 2012. Disponível em: <https:// portalrevistas.ucb.br/index.php/raead/article/view/3254>. Acesso em: 27 nov. 2018.

FILATRO, Andreia. Design instrucional na prática. São Paulo: Pearson/Prentice Hall, 2008.

GODOI, Eliamar; MIRANDA, Guacira. Alunos da educação a distância: comprometimento e autonomia no processo de aprendizagem. In: CietEnPED 2018. Anais... São Carlos: UFSCar, 2018. p. 1-10. Disponível em: <http://cietenped.ufscar.br/submissao/index.php/2018/article/view/903/481>. Acesso em: 14 ago. 2018.

GOMURY, Andreia S. Educação a distância com foco no aluno e as contribuições dos docentes para a autonomia no ensino-aprendizagem: o caso do design instrucional. In: CietEnPED 2018. Anais... São Carlos: UFSCar, 2018. p. 1-13. Disponível em: <http://cietenped.ufscar.br/submissao/index.php/2018/ article/view/217>. Acesso em: 16 ago. 2018.

JESUS, Paula Bettani M. de. Considerações acerca da noção de afeto em Spinoza. Cadernos Espinozanos, São Paulo, nº 33, p. 161-190, jul./dez. 2015.

MENDES NETTO, Cristiane; PÉPETUO, Denis Graciolli A. M. Estratégias para construção de relações afetivas em ambientes virtuais de aprendizagem. In: CONGRESSO INTERNACIONAL DE EDUCAÇÃO A DISTÂNCIA. Anais... Foz do Iguaçu: ABED, 2010, p. 1-10. Disponível em: http://www.abed.org.br/congresso2010/cd/252010085045.pdf. Acesso em: 27 nov. 2017.

MORAN, José Manuel. Interferências dos meios de comunicação no nosso conhecimento. Revista Brasileira de Comunicação, São Paulo, v. 17, n², p. 38-49, jul./dez., 1994. Disponível em: http://portcom. intercom.org.br/revistas/index.php/revistaintercom/article/viewArticle/844. Acesso em: 27 nov. 2018.

SAPUCAIA, Flavio dos Santos. Introdução à gestão tecnológica. O papel da gestão tecnológica e formação das equipes pedagógicas. São Paulo: Senac, 2017. Disponível em: <https://senacsp.blackboard. com/bbcswebdav/pid-2833506-dt-content-rid-71789978_1/courses/EGEADCASDA-1701-669480/Template/Aulas/Aula 06/PDF/INT GES TEC 06 PDF.pdf>. Acesso em: 10 nov. 2018. 
SPINOZA, Baruch. Ética. 2. ed. Trad. Tomaz Tadeu. Belo Horizonte: Autêntica, 2007. Formato Kindle.

VYGOSTSKY, Lev. O desenvolvimento psicológico na infância. Trad. Claudia Berliner. São Paulo: Martins Fontes, 1999.

WALLON, Henri. A evolução psicológica da criança. Trad. Cristina Carvalho. São Paulo: Martins Fontes, 2005. 